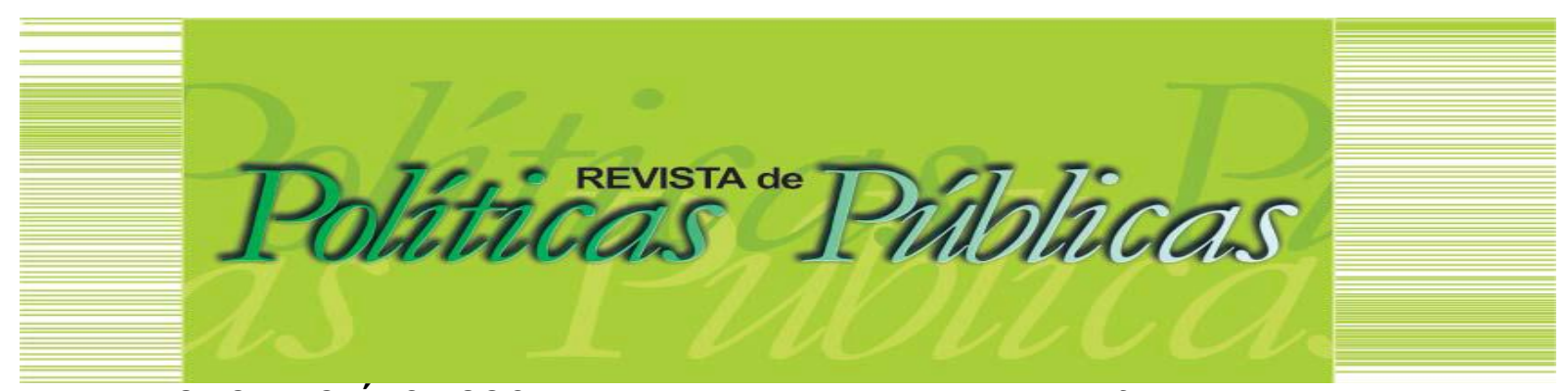

\title{
FAMILISMO E POLÍTICA SOCIAL: aproximações com as bases da formação sócio-histórica brasileira
}

\author{
Patricia Maccarini Moraes ${ }^{1}$ \\ Renata Nunes ${ }^{2}$ \\ Claudio Henrique Miranda Horst ${ }^{3}$ \\ Regina Célia Tamaso Mioto ${ }^{4}$
}

\section{Resumo}

O artigo problematiza a construção do familismo no Brasil como elemento estruturante da política social na formação sóciohistórica brasileira. Destaca a necessidade de entender a vinculação orgânica entre política social e família para afrontar sua naturalização na esfera da proteção social. Ao recorrer à formação sócio-histórica observa repercussões do período colonial e imperial na configuração da cultura política na fase republicana. Aponta que tais repercussões incidem sobre a proteção social e revelam a posição estratégica da família no desenvolvimento do capitalismo. 0 recuo histórico é fundamental para explicar a arquitetura do familismo e demonstrar sua atualidade na estruturação da política social. Ressalta, ainda, que perdura no país uma concepção de família conectada às bases de sua formação social e econômica e com papel fundamental na reprodução ideológica da sociedade brasileira.

Palavras - Chave: Familismo. Política Social. Formação Sócio-histórica.

FAMILISM AND SOCIAL POLICY: approaches with the bases of Brazilian socio-historical formation

\section{Abstract}

The article discusses the construction of familism in Brazil as a structuring element of social policy in Brazil's socio-historical formation. It highlights the need to understand the link between social policy and family to confront its naturalization in the sphere of social protection. By resorting to socio-historical formation, it is observed the repercussions of colonial and imperial periods in the configuration of political culture in the republican period. Such repercussions affect social protection and reveal the family's strategic position in the development of capitalism. The historical recap is key to explain the architecture of familism and to demonstrate its relevance in social policy. It is argued that persists in the country a concept of family connected to the basis of its social-economic formation and with a key role in the ideological reproduction of the brazilian society.

Keywords: Familism. Social Policy. Socio-historical Formation.

Artigo recebido em: 15/04/2020 Aprovado em: 25/10/2020

DOl: http://dx.doi.org/10.18764/2178-2865.v24n2p802-818.

\footnotetext{
1. Assistente social, Mestre e Doutoranda em Serviço Social pelo Programa de Pós-Graduação em Serviço Social da Universidade Federal de Santa Catarina. Assistente Social no Instituto Federal de Santa Catarina - IFSC, Campus Caçador. Pesquisadora integrante do Núcleo de Pesquisa Interdisciplinar Sociedade, Família e Políticas Sociais - NISFAPS, da Universidade Federal de Santa Catarina. E-mail: pmaccarinimoraes@gmail.com

2 Assistente Social Mestre e Doutoranda em Serviço Social pela Universidade Federal de Santa Catarina. Assistente Social da Secretaria de Estado de Assistência Social Trabalho e Habitação...E-mail: renata.net@gmail.com

${ }^{3}$ Assistente Social. Mestre em Política Social e Doutor em Serviço Social.Professor do Departamento de Serviço Social da Universidade Federal de Ouro Preto. E-mail: claudiovasques1@hotmail.com

${ }^{4}$ Assistente Social. Doutora em Saúde Mental pela Universidade Estadual de Campinas. Professora do Programa de PósGraduação em Serviço Social da Universidade Federal de Santa Catarina, onde integra o Núcleo de Pesquisa Interdisciplinar Sociedade, Família e Políticas Sociais (NISFAPS).. E-mail: regina.mioto@gmail.com
} 


\section{INTRODUÇÃO}

O declínio da era de ouro do Welfare State nos países do capitalismo central e seus rebatimentos nos países de capitalismo dependente - que nunca conseguiram aceder à condição de Estados de bem-estar - trouxeram à baila a questão da família no campo da política social. Temática, até então descurada no âmbito do debate brasileiro, toma fôlego a partir dos anos de 1990 e, particularmente, dos anos 2000, quando aparece incorporada explicitamente na política de assistência social. O mal-estar causado especialmente no meio acadêmico, por tal incorporação, pode ser associada a duas chaves. A primeira ao paradoxo que existe entre família e cidadania, pautada na ideia de direitos sociais universais, portanto vinculada a todas as pessoas, independente dos pertencimentos ou do filtro da família. A segunda pela escassa tradição do debate da família no contexto da política social, uma vez que as análises dos sistemas de proteção social foram concentradas nos eixos do Estado e do Mercado e suas inter-relações.

A incorporação da família no debate, além de referências clássicas como a de Beveridge que destaca a presença da família na estruturação da proteção social, particularmente das mulheres casadas (CAMPOS, 2015), toma força a partir dos anos de 1970 com os estudos feministas de tradição marxista. Estes vão colocar enfaticamente a família, além do trabalho, como pilar do welfare state. Mais que isso, vão enfatizar que tal estruturação só foi possível a partir do trabalho não pago das mulheres realizado dentro de um modelo de família conhecido como "male breadwinner model".

No Brasil, esse debate também se desenvolve a partir do movimento feminista, embora nem sempre reconhecido. No Serviço Social começa a se estruturar realmente com a incorporação da matricialidade sociofamiliar na política de assistência social e se espraia para análises em outros setores da seguridade social brasileira, como a política de saúde, além da previdência social e dos estatutos do idoso e da criança e do adolescente (CAMPOS; MIOTO, 2003).

Tal debate para a área do Serviço Social brasileiro, que tem uma vinculação orgânica com a Política Social e a família como instituição presente no trabalho profissional ao longo de sua história, parece fundamental por dois aspectos. Primeiro, para compreender as relações paradoxais existentes entre família e cidadania. Segundo, para entender a incorporação da família na política social e a sua naturalização, enquanto esfera central de proteção social, no contexto da crise atual do capitalismo. Contexto marcado pelo ideário neoliberal que se acentuou aceleradamente com o golpe parlamentar de 2016. Em relação ao segundo aspecto, torna-se importante buscar chaves explicativas, para além do escopo da política social, abrangendo os aspectos culturais, políticos, sociais e econômicos da formação social brasileira. 
FAMILISMO E POLÍTICA SOCIAL: aproximações com as bases da formação sócio-histórica brasileira

Nesse sentido, partimos da compreensão, conforme destacou Sereni (2013, p.303) que a categoria 'formação sócio-histórica' e/ou 'formação econômico-social', "expressa justamente, um processo, uma realidade dinâmica e não estática". Além desse destaque, conforme expressou o autor:

[...] esta categoria expressa a unidade (e, agregaremos, a totalidade) das diferentes esferas: econômica, social, política e cultural da vida de uma sociedade; e a expressa, além disso, na continuidade e ao mesmo tempo na descontinuidade de seu desenvolvimento histórico (SERENI, 2013, p.314, grifo nosso).

Diante do exposto, este artigo tem como objetivo problematizar a construção do familismo no Brasil, compreendido enquanto elemento estruturante da política social, no contexto da formação sócio-histórica brasileira1. Para tanto, o texto que ora se apresenta está organizado em duas seções, seguido das conclusões provisórias. A primeira seção busca retratar brevemente o debate sobre a família no contexto da proteção social a partir da última década do século $\mathrm{XX}$, particularmente no Serviço Social brasileiro, quando traz à tona o caráter familista da política social brasileira. A segunda esforça-se para fazer uma primeira aproximação com a formação sócio-histórica do país, que oferece pistas da constituição desse caráter que se expressa atualmente no cenário político nacional.

\section{A AFIRMAÇÃO DO CARÁTER FAMILISTA DA POLÍTICA SOCIAL BRASILEIRA}

A discussão em torno das relações entre família e política social no Brasil foi amplamente ancorada nas contribuições de autores europeus, que vinham trabalhando tais relações no contexto do welfare state. Como já assinalado, os estudos feministas de tradição marxista tornaram-se referências fundamentais no debate. Saraceno (1996), ao tratar dessas relações, alertava sobre a complexidade existente à medida que permanece uma grande dificuldade em estabelecer consensos nesse campo. Admite que mesmo existindo concordância sobre a importância das políticas sociais para sustentar a vida familiar, não existe consenso nem sobre o que é família e nem sobre o que se entende por sustentar a família.

Disso derivam discordâncias não triviais em torno de como se estabelecem as relações entre família e política social, considerando principalmente as diferentes conformações da "divisão" de responsabilidades no campo da reprodução social entre Estado e família. E, também, que as políticas sociais constituem importante canal de interferência do Estado na família, além da legislação e de outros setores do Estado. Além disso, para compreender tais relações, torna-se necessário identificar os níveis de análises possíveis, que para Saraceno (1997) seriam o debate sobre os mecanismos redistributivos, sobre o sistema família-serviços e sobre a divisão do trabalho familiar no interior das famílias. 
$\mathrm{Na}$ efervescência desse debate e nas críticas das feministas ao trabalho de Esping Andersen - The three worlds of Welfare Capitalism - de 1990 sobre a concentração de sua análise dos regimes de bem-estar nas esferas do mercado e do Estado, o referido autor, considerando tais críticas, escreve o seu livro Social foundations of post-industrial economies em 1999. Nele, agrega a família como esfera importante que concorre na conformação dos regimes de bem-estar. Essa obra marca a ampliação das análises sobre o Estado do Bem-estar Social realizada sob o paradigma da economia política dos anos de 1980 que tomava a família apenas de forma subsidiária, enquanto agente de 'desmercantilização' e beneficiária de efeitos distributivos, ou ainda como parte do interesse eleitoral. Esping-Andersen, ao incorporar o estudo da chamada economia das famílias, reescreve a sua teoria dos três mundos do Estado de Bem-Estar e, ao enfatizar as experiências dos países do sul da Europa (Portugal, Espanha, Itália e Grécia), aponta o familismo como um importante traço cultural na identificação e entendimento dos respectivos sistemas de proteção social (CARDOSO JR, 2003).

É justamente através dessa obra que o termo familismo é incorporado no debate sobre as relações entre política social e família no Brasil. Para Esping - Andersen o familismo está presente nos sistemas de proteção social à medida que "a política pública considera - na verdade insiste - em que as unidades familiares devem assumir a principal responsabilidade pelo bem-estar de seus membros" (ESPING-ANDERSEN, 1999, p. 5), o que corresponde a uma menor provisão de bem-estar por parte do Estado.

Nos Estados de caráter familista existe uma explícita parceria entre Estado e família, e 0 quantum de proteção assumido por cada um é que caracteriza maior ou menor grau de familismo. 0 oposto - desfamiliarização - segundo o autor. ocorre quando os regimes de bem-estar abrandam a responsabilidade familiar em relação à provisão de bem-estar social, seja através do Estado ou do mercado. Portanto, a desfamiliarização pressupõe a diminuição dos encargos familiares e a independência da família especialmente em relação ao parentesco, através de políticas familiares/sociais (MIOTO, 2009).

Essa discussão abriu o leque para o acesso a inúmeras outras contribuições que demonstravam a presença intensa da família na configuração dos padrões de proteção social, bem como as formas de incorporação da família na política social, tanto nos países de capitalismo central como dependentes. Tendência agravada quando o padrão de bem-estar keynesiano/beveridgiano deixa de ser a referência na condução das políticas sociais e reedita-se a tese liberal do Estado mínimo e do mercado enquanto instância reguladora da vida social. Nesse movimento acentua-se a diluição da responsabilidade coletiva da proteção social e recoloca-se em cena a tese da responsabilidade dos indivíduos, ou melhor, de suas famílias na provisão do bem-estar, denominado por De Martino (2001) de "neo-liberalismo familiarista". 
Esse movimento consiste, essencialmente, na "redescoberta" da autonomia familiar enquanto possibilidade de resolver seus problemas e atender suas necessidades. Ou seja, adota-se uma "solução familiar" para a proteção social. Porém, para Saraceno (1997) essa solução é inviável à medida que, além das altas taxas de desemprego, há o esgotamento das famílias para atender as exigências de proteção social. Um esgotamento que decorre do empobrecimento e das transformações na sua configuração demográfica. Portanto, a autora indica que a família atual está indisponivel para exercer as funções necessárias à proteção de seus membros, dadas as transformações sofridas por essa "velha" família com quem contavam - real ou idealizadamente - os vários sistemas de bem-estar social.

Na mesma direção, Pereira (1995; 2004) indica, no contexto da ascensão do pluralismo de bem-estar, a impossibilidade de a família assumir o protagonismo da proteção social considerando as suas características contemporâneas. Goldani $(1994 ; 2004 ; 2005)$ além de corroborar a indicação de Pereira (1995, 2004), demonstra a persistência das políticas sociais referidas à família no Brasil e a aposta nos contratos intergeracionais. As políticas referidas à família agrupam um conjunto de medidas e instrumentos que têm o objetivo de fortalecer suas funções sociais, seja a partir de sua estrutura, de suas características ou de demandas de seus membros. Recobrem, assim, tanto políticas de caráter universal, como as focalizadas no combate à pobreza, à violência doméstica, dentre outras.

Além disso, Carvalho e Almeida (2003) afirmam que no Brasil, apesar dos baixos salários, do desemprego e da inconstância dos serviços públicos, a família continua viabilizando a reprodução social através da lógica da solidariedade e de práticas dos grupos domésticos. Para elas, as famílias vêm exercendo, ao longo do tempo, o papel de amortecedor das crises do país, especialmente após os anos 1980. Contudo, Montali (2000). ao discutir as relações família e trabalho na reestruturação produtiva no Brasil, nos anos de 1990, alertava para a tendência de declínio dessa capacidade da família e, contraditoriamente, alimentava a manutenção do modelo de família do homem provedor.

Para corroborar o delineamento desse quadro, Campos e Mioto (2003) demonstram que as definições legais e operacionais das políticas sociais brasileiras definem a centralidade histórica da família na produção do bem-estar. Indicam que, tanto nos dispositivos legais como na operação de programas sociais, é clara no Brasil a dependência do reconhecimento do direito individual às condições da família, o que consagra o princípio do Estado como subsidiário em relação a ela, com exceção ainda da política de saúde.

Com isso, ampliam-se os questionamentos sobre as tendências da política social brasileira considerando a desigualdade estrutural do país e a lógica inaugurada pela Constituição Federal de 1988, do dever do Estado na provisão de bem-estar através da garantia dos direitos sociais. Esses questionamentos no campo do Serviço Social vêm abrangendo desde as contradições na 
formulação da política social até a proposição do trabalho social com família, explicito no contexto do Sistema Único de Assistência Social (SUAS).

Assim, adoção da matricialidade sociofamiliar, como diretriz da Política Nacional de Assistência Social (PNAS) e seus desdobramentos no âmbito do SUAS, desencadeou nos últimos dez anos uma série de pesquisas sobre a intervenção dos profissionais com famílias, muitas enfatizando os assistentes sociais, tanto no plano dos serviços socioassistenciais da proteção social básica, como na proteção social especial (ROMANO, 2009; CAMPOS, 2010; CASTILHO, 2012; SANTOS, 2010; CARRARO, 2011; TEIXEIRA, 2013; TEIXEIRA; CRONENBERG, 2014; GARCIA et al, 2014; JUNIOR, 2016). Os resultados de tais pesquisas apontam para a prevalência de uma intervenção de natureza conservadora tanto em termos das concepções de família adotadas quanto em relação às suas práticas dirigidas às famílias. No campo do Serviço Social, esses resultados são impactantes à medida que evidencia um distanciamento dos assistentes sociais das proposições defendidas pela categoria profissional a partir de seu projeto ético-político.

É justamente essa realidade, que descortina a presença do traço familista na política social brasileira e a sua reiteração na prática profissional, que tem instigado o aprofundamento dos estudos relacionados às concepções de família e a centralidade de seu papel no contexto da sociedade brasileira, particularmente na estruturação da proteção social. Em relação às concepções de família destaca-se que estas não se constroem apenas a partir de suas modulações, mas elas implicam, também, nos posicionamentos em relação ao seu papel na configuração dos sistemas de bem-estar social. Ou seja, insiste-se que as concepções de família contemplam pelo menos dois elementos: a sua morfologia, ou configuração concernentes à sua estrutura e relações e; às expectativas que se tem em relação a ela na provisão de bem-estar².

Essas expectativas estão diretamente relacionadas às concepções de igualdade e justiça que regem as formas de distribuição das responsabilidades entre as diferentes instâncias encarregadas pela provisão de bem-estar. É a partir desses elementos que são construídas diferentes concepções de família que estão na base de determinados consensos, que se expressam nos mais variados campos da vida social (MIOTO, 2015). Portanto, a hegemonia de uma concepção de família tanto na política social como nas práticas profissionais tende a expressar a própria cultura política brasileira.

Com isso, o conceito de familismo se alarga para além dos marcos dados por EspingAndersen e pode ser entendido como um padrão cultural e político secular que tem se expressado tanto no campo da legislação concernente à família como na configuração da política social. Uma configuração permeada tanto pela ausência de políticas que sustentem a vida familiar como pelas formas de incorporação da família na política social. Uma compreensão pautada em Batthyanny (2009), que acrescenta que o familismo é um padrão de inter-relação reinante na sociedade em que no nível 
macrossocial - organização dos sistemas de proteção social - a família é colocada como instituição provedora central de bem-estar e no nível microssocial uma rede de mulheres (mães, avós, vizinhas) respondem pelo trabalho familiar, especialmente pelo cuidado.

Considerando a persistência e a força que esse traço tem tido na definição dos rumos da política social brasileira e da prática profissional das/os assistentes sociais é que se busca entendê-lo nas bases sócio- históricas da sociedade brasileira.

\section{APROXIMAÇÕES COM AS BASES SÓCIO-HISTÓRICAS DO FAMILISMO NO BRASIL}

Ao debruçar sobre o tema da formação sócio-histórica brasileira é interessante observar a importância que é dada ao período colonial e as suas repercussões em períodos posteriores, particularmente no campo da cultura política do país. Mais instigante ainda é verificar a importância atribuída pelos estudiosos, de diferentes vieses teóricos, a dois aspectos. 0 primeiro, à família como centro da vida colonial, numa economia agrícola da grande propriedade e transpassada pelas relações com a Igreja e a Coroa portuguesa, como nos trabalhos clássicos - construídos a partir de diferentes perspectivas - de: Gilberto Freire - Casa Grande \& Senzala (1933); Sergio Buarque de Holanda Raízes do Brasil (1936); Caio Prado Junior - Formação do Brasil Contemporâneo (1942) entre outros como de Antônio Cândido - The Brazilian family (1951); e Jacob Gorender - Escravismo Colonial (1978).

O segundo aspecto, ao período de transição - da independência do Brasil à república que configura a mudança de uma organização social pautada nas relações mercantis das famílias "diretamente" com a coroa enquanto exportadoras de produtos agrícolas, em direção à organização do modo de produção capitalista, que implica na organização do Estado nacional, na conformação da ideia de Nação e do processo de urbanização. Enfim, período em que se estruturam as relações entre o privado e o público no Brasil e a construção da ideia de cidadania. São ícones na análise desse momento, além dos autores já citados, Raimundo Faoro com 'Os Donos do Poder - Formação do Patronato Político Brasileiro' de 1958; Jurandir Freire da Costa com 'Ordem médica e Norma Familiar' de 1978; Florestan Fernandes com 'A Revolução Burguesa no Brasil' de 1974; e José de Souza Martins com 'O Cativeiro da Terra' de 1979.

Florestan Fernandes (1987), ao analisar a transição e as transformações no Brasil, entendidos como processo de contrarrevolução burguesa, aponta que os eixos econômicos, sociais e políticos continuaram estruturados em torno da escravidão e da dominação patrimonialista. Para o autor, no Brasil a sociedade civil foi construída racial, social e economicamente ancorada nas relações coloniais. As dimensões de poder continuaram se estruturando em torno da figura do senhor colonial e 
das estratificações dos estamentos. Dessa forma, o Estado nacional emergiu fortemente vinculado à preservação da escravidão, do império e da dominação senhorial. No processo de conversão da sociedade colonial em sociedade nacional,

A correlação entre o 'velho' e o 'novo' evidencia que o Estado preenchia funções sociais manifestas em dois níveis distintos. As elites dos estamentos senhoriais precisavam dele, quase na mesma proporção: $1^{\circ}$ ) para manter as estruturas sociais que poderiam privilegiar seu prestígio social e, portanto, conduzi-las ao monopólio social do poder político; $2^{\circ}$ ) para expandir ou fomentar 0 aparecimento das condições econômicas, sociais e culturais que deveriam formar o substrato de uma sociedade nacional (FERNANDES, 1987, p. 47).

Nesses termos, desde os primórdios da organização do Estado nacional no Brasil sua função é garantir a dominação política dos senhores rurais. Ao analisar a relação entre estamentos dominantes e estamentos intermediários, Fernandes (1987) cita a presença de um elemento típico "[...] que era um membro de "famílias tradicionais" ou de "grandes famílias", que pertencia à sociedade civil, mas não possuía condição senhorial propriamente dita" (FERNANDES, 1987, p. 157). Esse elemento se integrava às elites econômicas, sociais e políticas pela via dos dotes pessoais ou por meio das necessidades criadas pela fusão entre patrimonialismo e burocracia. Em consequência dos privilégios conferidos ao senhor, o poder político sempre convergia para aqueles que possuíssem autoridade suprema na estrutura da família patriarcal e da dominação patrimonialista.

Nem mesmo a consolidação da Revolução Burguesa no Brasil, nos marcos de um capitalismo dependente e periférico que, sob o domínio imperialista, drena significativas parcelas do excedente econômico produzido internamente para fora, conseguiu minar o poder das oligarquias. Estas não perderam o poder que tinham como aristocracia agrária e conseguiram enfrentar a transição pela via da modernização conservadora, viabilizando acordos entre as elites (oriundos de estratos das "velhas" elites) para manter o caráter autocrático da dominação burguesa (FERNANDES, 1987).

Assim, constata-se que desde o período colonial, o status e o poder no âmbito político estiveram atrelados aos que tinham poder econômico, que derivava dos grandes grupos familiares tradicionais. Conforme destacou Pinheiro (2018), a simbiose desse processo histórico entre patriarcalismo e coronelismo retificava um poder privado que se instituiu na esfera pública. Nesse sentido,

[...] o desenvolvimento concentrado em âmbito rural e um projeto de colonização aperiódico promoveram também a possibilidade de construção de características como a legitimação do patriarca, a reprodução do coronelismo político e o conflito entre aquilo que são direitos sociais e o que são benesses de tom assistencialistas (PINHEIRO, 2018, p.8).

Como o Estado Nacional, nos termos apontados por Fernandes, se constrói profundamente atrelado a essas estruturas, não se desvincula da órbita de poder e de influências das grandes famílias coloniais e se consolida já sob a vigência das relações capitalistas em instrumento de 
defesa de interesses privados (nacionais e estrangeiros). Buarque de Holanda (2017), no seu Raízes do Brasil, é enfático ao afirmar que a entidade privada no Brasil precede a pública, à medida que a sombra do quadro familiar persegue os indivíduos mesmo fora do espaço doméstico. A "improvisada" burguesia urbana no Brasil, de acordo com o autor, nasce impregnada pela marca da família gerada pela colonização portuguesa. Ela traz na sua formação a incompatibilidade entre o patriarcalismo e personalismo fixados pela tradição e as formas de vida, copiada dos países mais avançados.

O desenvolvimento do capitalismo no Brasil terá peculiaridades importantes e a família será estratégica na conformação da burguesia nacional. Estratégica, de acordo com a análise de Costa (1999), para criar condições de sujeição política dos indivíduos para que o Estado capitalista de tipo dependente pudesse se estabelecer. O caminho para criação de tais condições foi o estabelecimento de uma relação intrínseca entre ordem médica e norma familiar. Segundo o autor, a medicina higiênica foi usada para desarticular o poder político dos latifundiários, minimizar as formas de solidariedade da família senhorial e o peso das relações de parentesco como apoio às relações de poder (ou seja, reestruturar o núcleo familiar) e subordinar os indivíduos ao Estado.

Porém, ao mesmo tempo costurou a oposição entre Estado e Família, na medida em que, atendendo aos interesses do Estado regulariza a família burguesa. Ou seja, as práticas higienistas foram utilizadas como forma de subordinar a população por meio da ação dos médicos no interior das famílias da elite, uma vez que elas eram um obstáculo à consolidação do Estado porque estavam atreladas à organização latifundiária típica do período colonial. Nas palavras do autor "O Estado aceitou medicalizar suas ações políticas, reconhecendo o valor político das ações médicas" (COSTA, 1999, p. 28).

Nesse processo, alteraram-se a casa e as relações de produção e consumo no interior das famílias, os papéis sociais dos membros do grupo familiar (homens, mulheres e crianças, com forte ênfase no papel dos filhos), e operou-se a construção do sentimento de intimismo, privacidade e amor. "A família converteu-se, de grande corpo socioeconômico, em célula da sociedade" (COSTA, 1999, p. 141, grifo do autor). As famílias passaram a se enxergar como responsáveis pela ordem e pelo desenvolvimento do Estado, identificando-se política, econômica e socialmente com ele. As relações intrafamiliares foram alteradas a fim de produzir uma organização familiar tutelada ao Estado e que consolidasse o projeto burguês de desenvolvimento. Em uma perspectiva ampliada, podemos dizer que a família desempenha funções estratégicas na sociedade, sendo reconfigurada a partir da emergência do capitalismo para contribuir com essa nova forma de organização social. Ademais, a formação social-histórica de cada país determina os matizes da função estratégica da família, nas diferentes relações estabelecidas com o Estado, em nosso caso, de capitalismo dependente. Além disso, as 
relações entre família e Estado também se constroem de forma diferenciada a depender da classe ou fração de classe a que pertence determinado grupo familiar.

Nesse contexto, é necessário ressaltar que o projeto higiênico se estendeu para toda a sociedade, mas teve impactos diferentes na vida das famílias da elite e das famílias da classe trabalhadora. No processo de construção da nação brasileira, Fonseca (2001) retrata a construção de uma organização familiar que possibilitasse as condições favoráveis ao desenvolvimento da nação.

[...] é a ideia do aprimoramento físico e moral da raça como condição de fortalecimento da nação. Para a consecução deste objetivo, a constituição de um certo tipo de família ocupa um lugar central. A família pensada como meio de formador de brasileiros fortes, moral e fisicamente [...] (FONSECA, 2001, p. 63).

A morfologia de família necessária para alcançar esse objetivo é a família nuclear patriarcal que, posteriormente, foi colocada sob proteção do Estado. Este deveria estabelecer as condições favoráveis à sua formação, desenvolvimento e segurança, numa racionalidade capaz de promover a construção e a solidificação de vínculos familiares e conduzir a uma solidariedade compulsória - processo que se materializou por meio do pagamento de abonos familiares, concessão de moradias populares, mecanismos de educação, controle do trabalho da mulher, entre outros.

Historicamente, o que se observa é a compreensão da família como um instrumento para transformar e corrigir a sociedade, como um mediador para a transformação do país em uma grande nação ${ }^{3}$. No que se refere ao Estado, a proteção que oferecia era legitimada pelo estado civil e pela descendência, de modo que não "[...] há projetos que aparem aqueles fora dos vínculos de parentesco que se expressam no casamento e na descendência legítima ou legitimada" (FONSECA, 2001, p. 89).

José de Souza Martins, ao estudar o colonato a partir da realidade paulista (forma de trabalho livre que aqui nasceu das ruínas da escravidão), demonstra que passamos do trabalho escravo para o trabalho livre, mas não necessariamente assalariado. Ou seja, o fim do trabalho escravo não resultou, conforme demonstra o autor, no regime de trabalho assalariado, mas, na coexistência de tempos sociais diversos entre si, sendo um deles o regime de colonato.

Nesse regime, uma das características centrais, é que o mesmo foi organizado em torno do trabalho familiar, o que deu a esse período uma característica própria. É possível compreender que junto à construção da ideologia do trabalho, como forma de assegurar a sujeição dos imigrantes a terra, garantir a política de eugenia e impedir o acesso a terra pelos negros/as - podemos falar da necessidade da ideologia da família. Entendida aqui como uma forma de materializar junto à necessidade do enriquecimento por via individual, o bem comum de toda família. Ou melhor, de assegurar que a lógica liberal do trabalho e do enriquecimento por esforço próprio seria possibilitada a partir da formação de uma família. Martins (2017, p. 201) inclusive aponta que "essas ideias 
sustentaram uma política de seleção de imigrantes. Famílias tiveram preferência em relação a imigrantes solteiros". Particularmente naquele momento estudado, aponta o autor: "[...] o modo de explorar a força de trabalho encerra, um modo de concretizar a dinâmica da população - nesse caso, concretamente, a imigração, a ideologia do imigrante e do imigrantismo centrados na família e no trabalho familiar" (MARTINS, 2017, p. 142, grifo do autor).

Assim, a família constituiu-se como espaço estratégico, por meio do qual se pode universalizar novos valores sociais, buscando formar indivíduos individualizados, domesticados e colocados à disposição da cidade e da pátria. Assim, o Estado passa a ter maior importância que a família, porém um Estado apropriado pela família burguesa e ordenador das famílias trabalhadoras. Nesse sentido, merece destaque o papel articulador do Estado que, segundo Osório (2014), é a única instituição moderna com capacidade de fazer com que interesses particulares possam parecer de toda a sociedade. Uma instituição que sintetiza costumes, valores e ainda projeta rumos e metas para toda a sociedade. Em continuação, afirma que o Estado se constitui como centro de poder político que atua essencialmente como articulador da produção e reprodução da sociedade, seja no campo material, social, político e ideológico. Nesse processo a família é central tanto para a reprodução material da classe trabalhadora como para a reprodução dos valores e da ideologia burguesa.

Margarete Rago (2014) é enfática quanto à utilização da família como estratégia de transmissão de valores, ao tratar das primeiras décadas do século $X X$, já no curso do processo de industrialização no Brasil. A autora considera que se buscou sutilmente formatar um tipo de trabalhador que atuasse segundo interesses do capital. Tal formatação não exclui as relações familiares dos trabalhadores; pelo contrário, essas passam a ser estratégicas para garantir o andamento da ordem instituída. Ademais, o disciplinamento e o adestramento do operário tornando-o mais dócil e produtivo implicaram também a imposição de um modelo imaginário de família funcional à sociabilidade capitalista. Para tanto, instituir hábitos, costumes e comportamento moralizadores, estratégicos para evitar possíveis resistências ao novo modelo de dinâmica social que se impunha. "A família nuclear, reservada, voltada para si mesma, instalada em uma acomodação aconchegante deveria exercer uma sedução no espírito do trabalhador, integrando-o ao universo dos valores dominantes" (RAGO, 2014, p.87).

Para a autora, nessa dinâmica, emerge um novo modelo de feminilidade, a esposa-donade-casa-mãe-de família que, como principal aliada dos médicos, deveria atentar para os detalhes da vida cotidiana de cada membro da família. Fato que nos indica que a dinâmica imposta pela "nova" fase de desenvolvimento exige importantes tarefas da família e, especialmente, da mulher. Essa base de constituição da nação brasileira terá consequências importantes no desenvolvimento da cidadania no Brasil, que será perpassada por relações de compadrio e apadrinhamento. A construção dessas 
relações entre famílias ancorava-se na "necessidade, num mundo hostil, de criar laços morais com pessoas de recursos, para proteger-se a si e aos filhos" (SLENES, 1997, p. 271).

Assim, reforçava-se e ampliava-se a solidariedade familiar e também o espectro da dominação. Nessas bases também foi se configurando a proteção social brasileira, na qual a família se constrói como uma instância ardilosa. Ela, na sua relação umbilical com a Igreja, se tornou os pilares que sustentaram um projeto de proteção social transpassado pelo princípio da subsidiariedade. Essa lógica só foi questionada frontalmente pela Constituição de 1988, quando a proteção social passou a ser concebida como dever do Estado, através da possibilidade da garantia dos direitos sociais. Concepção essa que parece ter tido uma curta primavera no contexto da sociedade brasileira, considerando os retrocessos persistentes desde o golpe parlamentar de 2016.

Esse golpe instaurou a quebra do compromisso com a Constituição Federal de 1988 em relação aos direitos sociais e demarca um novo período para a proteção social brasileira, sob a égide das políticas de austeridade e embaladas pela ideologia neoliberal. Assim, a família é novamente convocada a ser a grande protagonista, pois, como afirmam Vieira et al (2018), a política de austeridade está fundada na redução dos gastos públicos e do papel do Estado nas suas funções de indutor do crescimento econômico e promotor do bem-estar social. Nessa convocatória a família deve assumir compulsoriamente os custos da provisão de bem-estar. A partir de 2019 tal conjuntura se agrava ainda mais à medida que se associa a uma pauta reacionária de costumes. Esta tem expressão no legislativo através de projetos de lei que ganham força e visibilidade no Congresso Nacional como 0 Estatuto da Família (BRASIL, 2013) e o Estatuto do Nascituro (2007).

Atualmente, ressalta-se ainda a ação do Ministério da Mulher, Família e Direitos Humanos que, através da proposição de inúmeros programas que se arvoram atuar em "defesa" da família, das crianças e adolescentes,solapam as bases das políticas públicas sob os parâmetros da Constituição de 1988. Além do referido ministério, muitas outras ações e programas estão sendo desenvolvidos em outros ministérios que sustentam a concepção conservadora de família, tanto em relação a sua forma, como na sua responsabilidade em relação à provisão de bem-estar ${ }^{4}$. A manutenção dessa concepção de família é fundamental para sustentar as mudanças em curso e a superfocalização na família pobre em acordo com os interesses da elite brasileira e sob as orientações do Banco Mundial5.

Portanto, as particularidades da nossa formação econômica, política e cultural - de um país forjado a partir da escravização e do genocídio do seu povo - resultam em um emaranhado de determinações que reforçam uma cultura patriarcal, tradicionalista, preconceituosa que perpetuou características históricas na constituição de um certo modo de "ser família"6; como também de expectativas por parte de outras instituições da sociedade e do Estado na relação com a mesma. Materializados, fortemente, no caráter moralista e familista das diversas políticas sociais. 


\section{CONCLUSÕES}

Os breves e ainda incipientes elementos apresentados nos dão pistas de que o familismo no Brasil conta com particularidades próprias da formação social, onde se enraíza a política social brasileira. Os diferentes elementos da constituição do que chamamos de familismo parecem fazer parte da engrenagem das diferentes fases do desenvolvimento do capitalismo.

Disso deriva a compreensão de uma família profundamente conectada às bases da formação social e econômica do país, e com papel fundamental na reprodução ideológica da sociedade brasileira e, consequentemente, fortemente incorporada pela política social. Silva (1987), ao discutir a família no contexto das relações capitalistas, aponta para as funções da família no desenvolvimento das forças produtivas, que seriam: a) garantir a reprodução física e social dos indivíduos que constituirão a força de trabalho, devendo ser, portanto, compatíveis com as demandas do capital. Ou seja, nem tão escassa que ponha em risco os mecanismos de barateamento da força de trabalho, tornando-a cara, nem tão abundante que obrigue 0 investimento em serviços superiores aos adequados à formação de excedente ou alterações na dinâmica salarial; b) assegurar a manutenção dos filhos dentro da família, evitando a transferência do custo social de sua manutenção para a sociedade em geral; c) moldar a consciência dos indivíduos para que aceitem a dinâmica do processo, os valores de modernização, a necessidade da mobilidade física e a hierarquia necessária à produção, assim como aceitem a ideologia da propriedade privada, da divisão do trabalho (em geral e segundo os sexos); d) confirmar que o grupo familiar se caracterize como uma unidade de consumo.

O recuo histórico na formação social brasileira segue no esforço de explicar a arquitetura do familismo nessa particularidade e compreender as diferentes funções da família da classe burguesa e da família da classe trabalhadora, que se revelam estratégicas na constituição das relações capitalistas no Brasil. Afinal, conforme destacou lamamoto $(2001$, p.37) "[...] o discurso neoliberal tem a espantosa façanha de atribuir título de modernidade ao que há de mais conservador e atrasado na sociedade brasileira: fazer do interesse privado a medida de todas as coisas, obstruindo a esfera pública, a dimensão ética da vida social [...]". Essa coexistência de temporalidades históricas desiguais, conforme apontou a autora, faz com que a "questão social" apresente tanto marcas do passado quanto do presente, radicalizando-as.

Nesse sentido, faz-se urgente que a reflexão contemporânea sobre o trabalho profissional tome "um banho de realidade brasileira" (IAMAMOTO, 2001). É com base nesse entendimento que as reflexões apresentadas no presente texto nos parecem importantes para o enfrentamento das concepções conservadoras que são reiteradas nas práticas profissionais, entre as quais do Serviço Social, que persistem no campo da política social. 


\section{REFERÊNCIAS}

BATTHYÁNI, D. K. Cuidados de personas dependientes y género. In: AGUIRRE, R. Las bases invisibles del bienestar social: el trabajo no remunerado en Uruguay. Montevideo: UNIFEM, 2009. p. 87-124.

BRASIL. Projeto de Lei 6583/2013. Câmara dos Deputados. Disponível em: https://www.camara.leg.br/proposicoesWeb/prop_mostrarintegra?codteor=1159761. Acesso em: 21 nov. 2019

BRASIL. Projeto de Lei N. ${ }^{\circ}$ 478-A/ 2007. Disponível em: https://www.camara.gov.br/proposicoesWeb/prop_mostrarintegra;jsessionid=7FDC2C1C8D0C7075A8F 616AC66040D4E.node2?codteor=1102104\&filename=Avulso+-PL+478/2007. Acesso em: 24 mar. 2020.

CAMPOS, L. G. 0 trabalho com famílias na proteção social especial de média complexidade no município de Londrina/Pr. Dissertação (Mestrado). Programa de Pós Graduação em Política Social. UEL. Londrina, 2010, $132 \mathrm{f}$.

CAMPOS, M. S. O Casamento Da Política Social com a Família: feliz ou infeliz? In: MIOTO, R.C.T.; CAMPOS, M. S.; CARLOTO, C. M.(orgs.). Familismo, direitos e cidadania: contradições da política social. São Paulo: Cortez Editora, 2015, p. 21-43.

MIOTO, R. C. T. Política de Assistência Social e a posição da família na política social brasileira. Ser Social: Revista do Programa de Pós-Graduação em Política Social, UnB, Brasília, $n^{0} 12$, janeiro a junho de 2003, ISSN 1415-6946, p. 165-190.

CANDIDO, Antonio. "The Brazilian family". In: SMITH, T. Lynn \& MARCHANT, Alexander (orgs.). Brazil: portrait of half a continent. Nova York, The Dryden Press.1951.

CARDOSO JR, José Celso. Fundamentos Sociais das Economias Pós-industriais: uma Resenha Crítica de Esping-Andersen. Revista Brasileira de Informação Bibliográfica em Ciências Sociais. São Paulo, $n^{0}$ 56, $2^{\circ}$ semestre de 2003, p 71-92.

CARVALHO, I.; ALMEIDA, P. Família e Proteção Social. São Paulo em Perspectiva. São Paulo, n.17, v.2, p.109-122, 2003.

CARRARO, G. As pesquisas avaliativas de políticas sociais públicas: um estudo sobre a metodologia do trabalho com famílias no SUAS. Dissertação (Mestrado). Programa de PósGraduação em Serviço Social. Pontifícia Universidade Católica do Rio Grande do Sul. 2011, $226 f$.

CASTILHO, C. F. V. A operacionalização do trabalho social com famílias nos CRAS no município de Londrina/Pr. Dissertação (Mestrado). Londrina: Universidade Estadual de Londrina. 2012, $161 \mathrm{f}$.

COSTA, Jurandir Freire. Ordem médica e norma familiar. 4. ed. Rio de Janeiro: Edições Graal, 1999. $282 p$.

DE MARTINO, M. Políticas Sociales y Família: Estado de Bienestar y Neoliberalismo Familiarista. Fronteiras, Montevidéu, Uruguay, $\mathrm{n}^{\circ} 4$, set. - 2001, p. 103-114. 
ESPING-ANDERSEN, G. The three worlds of Welfare Capitalism. Cambridge: Polity Press, 1990. Social foundations of post industrial economies. New York: Oxford University Press, 1999.

FAORO, R. Os Donos do Poder - Formação do Patronato Político Brasileiro. 5.ed. São Paulo: Globo, 2012.

FERNANDES, F. A revolução burguesa no Brasil: ensaio de interpretação sociológica. 3. ed. Rio de Janeiro: Guanabara, 1987. 413 p.

FREYRE, G. Casa-grande e senzala. Lisboa, Livros do Brasil, 1957.

FONSECA, A. M. M. da. Família e política de renda mínima. São Paulo: Cortez, 2001.

GARCIA, J.; FREITAS, R.; MORGADO, R.; SENNA, M. de C. M.; OLIVEIRA, A. C. de. Desafios do trabalho com famílias na Política de Assistência Social. In: Anais do XIV Encontro Nacional de pesquisadores em Serviço Social: Lutas Sociais e Produção do Conhecimento. Natal: ENPESS, 2014.

GOLDANI, A. M. As famílias brasileiras: mudanças e perspectivas. Cadernos de Pesquisa. n. 91.1994, p.7-22.

GOLDANI, A. M. Reinventar políticas para as famílias reinventadas: entre la "realidad" brasileña y la utopia. Lineamientos de acción y propuestas de políticas hacia las famílias. Serie Seminarios y Conferencias, Chile, n. 46, CEPAL, p.319-345, 2005. Disponível em: http://www.pasa.cl/wpcontent/uploads/2011/08/Reinverntar_politicas_para_familias_reinventadas_Goldani_Ana_Maria.pdf.

Acesso em: 12 fev 2014.

Contratos intergeracionais e Reconstrução do Estado de Bem Estar. Por que se Deve Repensar essa Relação para o Brasil. In: CAMARANO Ana Amélia (org.). Os novos idosos Brasileiros: Muito além dos 60? Rio de Janeiro: IPEA, 2004. Disponível em: http://www.abep.nepo.unicamp.br/docs/PopPobreza/goldaniAnaMariaCapitulo7.pdf.

GORENDER, J. 0 escravismo colonial. 6 Ed. São Paulo: Expressão Popular: Perseu Abramo, 2016.

HOLANDA, S. B.de. Raízes do Brasil. 27 ed. São Paulo: Companhia das Letras, 2017

IAMAMOTO, M. O Serviço Social na Contemporaneidade: trabalho e formação profissional. 5. Ed. São Paulo, Cortez, 2001.

JUNIOR, A. A. S. A assistência social e as ideologias do social liberalismo: tendências políticopedagógicas para a formação dos trabalhadores do SUAS. Tese (Doutorado em Serviço Social) Universidade Federal de Pernambuco. 2016.

MARTINS, J. S. O Cativeiro da Terra. 9.ed. 3 reim. São Paulo. Contexto, 2017.

MIOTO, R. C. T.. Família e políticas sociais. In: BOSCHETTI, Ivanete et. al. (org.). Política social no capitalismo: tendências contemporâneas. 2. ed. São Paulo: Cortez, 2009. p. 130-148. 
O avanço do conservadorismo na Seguridade Social e as implicações na concepção de família. $5^{\circ}$ Encontro Nacional de Seguridade Social. Belo Horizonte: CFESS, 2015.

MONTALI, L. Família e trabalho na reestruturação produtiva: ausência de política de emprego e deterioração de condições de vida. Revista Brasileira de Ciências Sociais. São Paulo, Anpocs, v.15, n 42, p.55-75,fev. 2000.

ESCORSIM NETTO, L. O conservadorismo clássico: elementos de caracterização e crítica. São Paulo: Cortez, 2011.

PEREIRA, P. A. P. Pluralismo de Bem-Estar ou configuração plural da política social sob o Neoliberalismo. In: BOSCHETTI, I et. al (orgs.). Política social: alternativas ao neoliberalismo. UNB. Programa de Pós-Graduação em Política Social. Departamento de Serviço Social, 2004.

- Desafios Contemporâneos para a Sociedade e a Família. Serviço Social e Sociedade, 48, 103- 114. São Paulo: Cortez, 1995.

PINHEIRO, P. W. M. Tradição, Família e Propriedade": Questão Social, Formação Sócio-Histórica do Brasil e Conservadorismo sob a marcha da Contradição. In: Anais do XVI ENPESS, 2018.

PRADO Jr, C. Formação do Brasil Contemporâneo. 12 ed. São Paulo: Brasiliense, 1972.

OSÓRIO. J. O Estado no Centro da Mundialização: A sociedade civil e o tema do poder. São Paulo: Expressão Popular, 2014.

RAGO, Margareth. Do cabaré ao lar: a utopia da cidade disciplinar: Brasil 1890-1930. 4. ed. São Paulo: Paz e Terra, 2014.

ROMANO, A. P. H.. Entre socialização da informação e a organização coletiva: a dimensão socioeducativa na atuação com grupos nos CRAS em São José do Rio Preto/SP. Dissertação (Mestrado). Franca: UNESP, 2009, 238f.

SANTOS, R. 0 desafio do trabalho com famílias na política de assistência social no Vale do Paraíba. Dissertação (Mestrado)- Programa de Pós-graduação em Serviço Social, Pontifícia Universidade Católica de São Paulo, São Paulo. PUCSP- São Paulo 2010, 127p.

SARACENO, C. Sociologia della famiglia. Bologna: II Mulino,1996. Le compatibilità sociali nella riforma del welfare. In: Animazione Sociale, 6/7, Italia, 1997.

SERENI, E. De Marx a Lênin: a categoria de "formação económico-social". In: Revista de Geografia: Meridiano. Número, 2, 2013.

SILVA, L. M. M R. Serviço social e família: a legitimação de uma ideologia. 3. ed. São Paulo: Cortez, 1987.

SLENES, R. W. "Senhores e subalternos no Oeste Paulista". In: ALENCASTRO, Luiz Felipe de (org.) História da vida privada no Brasil. Império: a corte e a modernidade nacional. São Paulo: Companhia das Letras, 1997. 
TEIXEIRA, S. M. A Família na política de Assistência Social: concepções e as tendências do trabalho social com familia nos CRAS de Teresina-PI. Teresina: EDUFPI, 2013. 218p.

; CRONEMBERGER, I. H. M. Política de Assistência Social: as direções da matricialidade sociofamiliar e do trabalho social com famílias. Serviço Social em Revista, v. 16, n.2. Londrina: UEL. 2014, p.97-118.

VIEIRA, F.S.; SANTOS, I.S.; OCKÉ- REIS, C.; RODRIGUES, P.H.A. Políticas sociais e austeridade fiscal: como as políticas sociais são afetadas pelo austericídio da agenda neoliberal no Brasil e no mundo. Rio de Janeiro: CEBES, 2018, 64 p.

\section{Notas}

10 presente artigo é fruto de uma versão revisada e ampliada de texto originalmente publicado nos anais do ENPESS de 2018, sob o título: O Familismo na Política Social: Aproximações com as Bases da Formação Sócio-Histórica Brasileira. Anais do XVI Encontro Nacional de Pesquisadores em Serviço Social. Vitória: ABEPSS, 2018.

2 Conforme destacou Pinheiro (2018, p.11): "As peculiaridades da construção e dos entendimentos dos conceitos de família, embora pareçam dentro do senso comum algo dado e referendado no âmbito privado e constituído de aspectos singulares são, na verdade, dotados de elementos capciosos, frutos e reprodutores de visões de mundo, condutas e valores distintos que sofrem influências dessa formação sócio-histórica do país".

3 Conforme sabemos, a valorização da família está conectada a um dos traços constitutivos do conservadorismo. 0 pensamento conservador compreende que somente tais grupos intermediários asseguram a "harmonia orgânica da sociedade" (ESCORSIM NETTO, 2011). Tal traço constitutivo do nosso percurso sócio histórico constituiu o mote central da campanha eleitoral e do governo Bolsonaro em voga no Brasil. Tal tendência conservadora - familista, pode ser observada na substituição do Ministério dos Direitos Humanos pelo Ministério da Mulher, da Família e dos Direitos Humanos. Ou, pela instituição da Secretaria da Família que criou programas e campanhas como o Observatório Nacional da Família e o selo Empresa Amiga da Família. A Secretaria Nacional da Família sob comando da advogada Ângela Gandra explicitou a tendência familista do Ministério: "A proposta da Secretaria da Família é "diametralmente oposta" à ideia de intromissão do Estado na esfera privada. $O$ foco na família significa oferecer as bases para que a família possa consolidar-se internamente, sem que políticas públicas orientem suas decisões de forma pragmática e, na maioria das vezes, paternalista e ineficiente". Ver: https://www.gazetadopovo.com.br/vida-e-cidadania/o-que-bolsonaro-fez-na-defesa-da-familia-2019.

4 Exemplo disso é o Programa Conta Pra Mim lançado em 2019 pelo Ministério da Educação no âmbito da Política Nacional de Alfabetização. $O$ programa sugere que as famílias realizem diversas atividades para estimular a literacia familiar, tais como leitura, escrita, narração de histórias e outras formas de interação para alfabetizar as crianças. Tal programa parece estar deslocado das reais condições de vida da maioria das famílias brasileiras, que nem sempre favorecem o desempenho de tais práticas.

5 Outro exemplo é a proposta Como Investir na Primeira Infância: Um Guia para a Discussão de Políticas e a Preparação de Projetos de Desenvolvimento da Primeira Infância. Disponível em http://www.mds.gov.br/webarquivos/publicacao/crianca_feliz/Como_Investir_na_Primeira_Infancia.pdf.

6 "Os valores e costumes dominantes constituídos ao longo da história no Brasil se apresentam como derivações que são influenciados pelo modelo patriarcal, naturalizando a heterossexualidade como única forma de orientação sexual, a branquitude como modelo e a família nuclear como possibilidade exclusiva" (PINHEIRO, 2018, p.15). 